\title{
Suppression of Magnaporthe oryzae and interaction between Bacillus subtilis and rice plants in the control of rice blast
}

\author{
Yuexia Sha ${ }^{1,2}$, Qi Wang ${ }^{1,2^{*}}$ and Yan $\mathrm{Li}^{1,2}$
}

${ }^{*}$ Correspondence:
wangqi@cau.edu.cn
${ }^{1}$ Department of Plant
Pathology, China Agricultural
University, 2 West
Yuanmingyuan Rd., Haidian
District, Beijing 100193, China
Full list of author information
is available at the end of the
article

${ }^{*}$ Correspondence:

wangqi@cau.edu.cn

Pathology, China Agricultural

University, 2 West

Yuanmingyuan Rd., Haidian

District, Beijing 100193, Chin

is available at the end of the

\begin{abstract}
Magnaporthe oryzae, the causative pathogen of rice blast, has caused extensive losses to rice cultivation worldwide. Strains of the bacterium Bacillus subtilis have been used as biocontrol agents against rice blast. However, little has been reported about the interaction between B. subtilis and the rice plant and its mechanism of action. Here, the colonization process and induced disease resistance by B. subtilis SYX04 and SYX20 in rice plants was examined. Strains of $B$. subtilis labeled with green fluorescent protein reached population of more than $5 \times 10^{6} \mathrm{CFU} / \mathrm{g}$ after 20 days on mature rice leaves and were detected after 3 days on newly grown leaves. Results showed that SYX04 and SYX20 not only inhibited spore germination, germ tube length, and appressorial formation but also caused a series of alterations in the structures of hyphae and conidia. The cell walls and membrane structures of the fungus showed ultrastructural abnormalities, which became severely degraded as observed through scanning electron microscopy and transmission electron microscopy. The mixture of both B. subtilis and M. oryzae resulted in enhanced activity of peroxidase, and polyphenol oxidase while there was significantly more superoxide dismutase activity in plants that had been sprayed with B. subtilis alone. The present study suggests that colonized SYX04 and SYX20 strains protected rice plants and exhibited antifungal activity and induced systemic resistance, thus indicating their potential biological control agents.
\end{abstract}

Keywords: Bacillus subtilis, Magnaporthe oryzae, Rice plant, Colonization, Antifungal activity, Defense enzymes

\section{Background}

Rice (Oryza sativa), an important staple food crop, is cultivated on over 160 million hectares worldwide. It provides the daily energy for over 3.5 billion people (Skamnioti and Gurr 2009; FAO 2012; Muthayya et al. 2014). Rice blast caused by Magnaporthe ory$z a e$, spread in more than 85 countries and has caused great yield loss. Some $30 \%$ of the annual rice harvest is lost due to rice blast infection, enough rice to feed more than 60 million people for 1 year (Dagdas et al. 2012). Chemical pesticides, though effective in blast control (Yamaguchi 2004), involve residual toxicity and environmental pollution. Unlike applications of chemical fungicides, the use of biocontrol bacteria can involve mixtures of antifungal compounds, produced by the bacterium in amounts that fluctuate based on environmental cues (Hoitink and Boehm 1999).

(c) 2016 The Author(s). This article is distributed under the terms of the Creative Commons Attribution 4.0 International License (http://creativecommons.org/licenses/by/4.0/), which permits unrestricted use, distribution, and reproduction in any medium, provided you give appropriate credit to the original author(s) and the source, provide a link to the Creative Commons license, and indicate if changes were made. 
Interactions between biocontrol agents and pathogens have been studied in rice (Zarandi et al. 2009) and other commercially important crops (Anand et al. 2010). Yan et al. (2015) studied the interactions between fungi and bacteria in rice and found that Burkholderia gladioli strain could have a competitive superiority with Aspergillus flavus strain. Kumar et al. (2013) analyzed interactions between Bacillus subtilis MBI 600 and Rhizoctonia solani planta and found that strain MBI 600 suppressed its fungal partner effectively. The present study evaluated interactions between antagonistic bacteria and phytopathogens. Results showed Pseudomonas fluorescens 2137 to be highly effective in suppressing Fusarium culmorum on barley roots (Strunnikova et al. 2015). The genus Bacillus has considerable possible uses in agriculture. The antifungal properties of Bacillus species, including B. subtilis, have been investigated for their importance to the biological control of a number of plant and animal diseases (Grover et al. 2010). In addition, beneficial effects conferred by Bacillus strains act directly through several different biocontrol mechanisms, such as colonizing plants, forming biofilms, and enhancing the provision of nutrients and phytohormones, though they can also rely on other mechanisms, including antifungal activity and induced systemic resistance. A few studies have investigated the impact of $B$. subtilis. The colonization of $B$. megaterium (Liu et al. 2006) and strains of B. methylotrophicus (Shan et al. 2013) in rice plants has also been reported to have antifungal activity and to induce systemic resistance towards rice blast. In another study, higher levels of the PR proteins (PR2, PR6, PR15, and PR16) were observed in rice leaves inoculated with B. subtilis CB-R05 compared with the untreated control, indicating their potential for use in the biological control of the disease (Ji et al. 2014).

It is vitally important to develop successful and lasting solutions to crop loss caused by plant diseases. Understanding the global effect of biocontrol bacteria on phytopathogens may greatly increase the size and safety of the global food supply. In previous studies, several bacteria were isolated from rice cultivar Rejingyou No. 35 from Southwest Territories of China, which not only improved plant growth, but also suppressed M. oryzae. B. subtilis strains SYX04 and SYX20 have been characterized, and their antifungal activities against indicator fungi pathogen $M$. oryzae P131 have been demonstrated and found to be efficient. In a 2-year field experiment performed at several different locations, the use of B. subtilis SYX04 and SYX20 reduced the incidence of leaf blast by 73.5-83.5\% and that of panicle blast by $64.0-85.6 \%$ (Sha et al. 2014). This effect was similar to the use of $75 \%$ tricyclazole wettable powder. These strains have considerable prospects for use as a new tool for the biocontrol of rice blast. The purpose of the present study was to clarify bio-control mechanisms of B. subtilis against M. oryzae P131. To our knowledge, this is the first detailed report of the interaction between GFP-tagged B. subtilis and rice plant was performed towards the control of rice blast.

\section{Methods}

\section{Bacterial strains and plasmids}

Bacillus subtilis SYX04 and SYX20 (GenBank Accession Number: KJ848470 and KJ84847) were isolated from rice leaves at the Key Laboratory of Plant Pathology, China Agricultural University. The shuttle vector pGFP78 for Escherichia coli-B. subtilis containing GFP $(\mathrm{Dh} 5 \alpha)$ and tetracycline $(50 \mu \mathrm{g} / \mathrm{mL})$ resistance genes (Dunn and 
Handelsman 1999; Tian et al. 2004) was used as described by Li et al. (2000). Construction of GFP-labeled B. subtilis SYX04 and SYX20 were prepared as previously described (Li et al. 2000).

\section{Co-culture assays of B. subtilis and M. oryzae $\mathrm{P} 131$}

Bacillus subtilis was cultured in LB broth $(300 \mathrm{~mL} / \mathrm{L}$ in a liter flask) until OD600 values reached 1.0-1.2. Then liquid culture was centrifuged at $15 \mathrm{~kg}$ for $15 \mathrm{~min}$ at $4{ }^{\circ} \mathrm{C}$ and filtered by $0.22 \mu \mathrm{m}$ biofilter for culture filtrate. M. oryzae P131 was incubated on tomatooat medium for 9 days. Then, the petri dishes were washed twice with sterile water for spore suspension. The co-culture experiments were carried out in liquid culture of B. subtilis SYX04 or SYX20 $\left(1 \times 10^{8} \mathrm{CFU} / \mathrm{mL}\right)$ and M. oryzae P131 spore suspension $\left(1 \times 10^{6} \mathrm{cell} / \mathrm{mL}\right)$ or culture filtrate and $M$. oryzae P131 spore suspension in the same shake-flasks at $28{ }^{\circ} \mathrm{C}$ at a $1: 1$ volume ratio. The co-culture samples were incubated for 4 , 8,12 , and $24 \mathrm{~h}$ in culture conditions as described previously. All procedures described above were carried out under sterile conditions.

\section{Population dynamics of GFP-tagged SYX04 and SYX20}

Rice cv. Lijiangxintuanheigu (LTH) was used as a host plant (Kobayashi et al. 2007) susceptible to M. oryzae P131. Rice seeds were surface-sterilized by $1 \%$ sodium hypochlorite solution for $20 \mathrm{~min}$ and $75 \%$ ethanol for $10 \mathrm{~min}$ and then washed 3 times with sterile water. Finally, rice seeds that had been soaked in sterile water were germinated in a sterile petri dish for 2 days at $28{ }^{\circ} \mathrm{C}$ in a growth cabinet. When rice seeds reached approximately $1 \mathrm{~cm}$ in length, all seedlings were planted in sterile soil buckets and cultured in greenhouse. At the rice tillering stage (planted about 60 days), the plants were sprayed with GFP-labeled B. subtilis suspensions $\left(1 \times 10^{8} \mathrm{CFU} / \mathrm{mL}\right)$ or water inoculation for the negative controls. Each treatment group included twelve plants. Each bucket had three rice plants and each bucket was sprayed with $50 \mathrm{~mL}$ suspensions. The colonization dynamics was tested on leaves at 1, 3, 5, 7, 14, and 20 days post-transplant. Rice leaves were weighed (fresh weight $1 \mathrm{~g}$ ), then grinded in a sterile mortar with $4 \mathrm{~mL}$ sterile water and a small amount of sterile quartz sands. Finally, samples were grounded in a conical flask with $96 \mathrm{~mL}$ sterile water and allowed to be incubated with shaking for $30 \mathrm{~min}$, and the supernatant was diluted to $1: 10^{3}$ and spread on a petri dish.

\section{Impact of $B$. subtilis on fungal cell}

The following procedure was performed to determine the inhibitive effect of B. subtilis on fungal spore germination, germ length, and appressorial formation. Spore germination and morphological changes to the co-culture samples were monitored microscopically using centrifuge tubes. These co-culture samples were observed under an Olympus DP71 microscope. Images were captured using an Olympus digital camera, exported as TIFF files, and adjusted with Corel PHOTO-PAINT X6 software (Corel Corp, Ottawa, Ontario, Canada). All experiments were performed in triplicate. The relative number of germinated conidia, germ tube length, and appressorial formation were investigated by light microscopic examination of at least 100 spores per replicate (Zhang et al. 2013). Inhibition of spore germination, germ tube formation, and appressorial formation were calculated from the test data as follows: 
Inhibition $(\%)=100 \times(A-B) / A$

where $A$ and $B$ are the relative numbers of germinated spores, germ tubes, and appressoria in the control and test samples, respectively.

\section{SEM and TEM examinations}

For scanning electron microscopy (SEM) examination, the co-culture samples that blended B. subtilis SYX04 and SYX20 cells $\left(1 \times 10^{8} \mathrm{CFU} / \mathrm{mL}\right)$ and spore suspension of $M$. oryzae $\mathrm{P} 131\left(1 \times 10^{6} \mathrm{CFU} / \mathrm{mL}\right)$ by the same volume were incubated for $12 \mathrm{~h}$ in culture conditions as described previously, and M. oryzae P131 without B. subtilis cells served as a control. The conidial and hyphal structures of $M$. oryzae P131 inhibited by B. subtilis SYX04 and SYX20 cells were fixed in $4 \%$ glutaraldehyde at $4{ }^{\circ} \mathrm{C}$ for $16 \mathrm{~h}$, dehydrated, and coated with gold as described previously (Kong et al. 2012). The samples were observed with an S-3400N (Hitachi, Tokyo, Japan) scanning electron microscope as previously described (Kong et al. 2012). For transmission electron microscopic (TEM) examination, the co-culture samples that contained both B. subtilis SYX04 or SYX20 cells $\left(1 \times 10^{8} \mathrm{CFU} / \mathrm{mL}\right)$ and spore suspension of $M$. oryzae P131 $\left(1 \times 10^{6} \mathrm{CFU} / \mathrm{mL}\right)$ at the same volume were incubated for $4,8,12$, and $24 \mathrm{~h}$ in culture conditions as described previously, and the co-cultures without $B$. subtilis cells served as a controls. The conidial and hyphal structures of $M$. oryzae P131 were fixed, dehydrated, and embedded as previously described (Mariné 1992). The samples were made into ultrathin sections approximately $60 \mathrm{~nm}$ thick with an ultramicrotome (UC-7; Lecia Inc., Wetzslar, Germany). Serial thin-sections were removed onto slot grids and observed with a JEM-1230 transmission electron microscope (JEOL Ltd., Tokyo, Japan).

\section{Assay of defense enzymes}

At 20 days after growing in a plant growth cabinet at $28{ }^{\circ} \mathrm{C}$ and $12 \mathrm{~h}$ light per day, rice plants were sprayed with $1 \times 10^{8} \mathrm{CFU} / \mathrm{mL}$ bacterial cells and $1 \times 10^{6} \mathrm{CFU} / \mathrm{mL}$ suspensions of $M$. oryzae P131. Rice leaf samples were collected at different times after inoculation (1, 2, 3, 4, 5, and 6 days). Each replication had six plants sprayed with bacterial cells, or suspensions of $M$. oryzae P131, or mixture of bacterial cells and suspensions of $M$. oryzae P131. The experiments were performed using completely randomized designs, six treatments, and four replicates per treatment. The experimental treatments were as follows: treatment with a mixture of fermentation broth of SYX04 and pathogen infection (BP); treatment with a mixture of fermentation broth of SYX20 and pathogen infection (MP); treatment with a fermentation broth control of SYX04 (BC); treatment with a fermentation broth control of SYX20 (MC); treatment with a M. oryzae P131 control (PC); and treatment with sterile water control (UC). Peroxidase (PO) activity was detected as described by Hammerschimidt et al. (1982), by measuring absorbance at $470 \mathrm{~nm}$. Polyphenol oxidase (PPO) activity was examined as described by Li and Steffens (2002), by measuring absorbance at $420 \mathrm{~nm}$. The changes in absorbance (OD) for PO and PPO measurements were assayed at $30 \mathrm{~s}$ intervals for up to $3 \mathrm{~min}$ and are expressed in terms of $\mathrm{U} / \mathrm{g} / \mathrm{min}$ of protein. Superoxide dismutase (SOD) activity was examined as described by Dhindsa et al. (1981) by measuring absorbance at $560 \mathrm{~nm}$. One unit of SOD denotes the amount of enzyme that inhibits the NBT photoreduction by $50 \%$, and the 
enzyme was quantified based on the relative amount of inhibition. The enzyme activity of SOD is here expressed in terms of unit/g of protein.

\section{Statistical analysis}

All treatments were designed in four replicates. All analysis were carried out by the LSD's test $(P \leq 0.05)$ following one-way ANOVA using the SPSS 19.0 software for Windows (SPSS Inc., Chicago, IL, US).

\section{Results}

\section{Population dynamics of $B$. subtilis SYX04 and SYX20 colonization of rice plants}

Almost $1 \times 10^{8} \mathrm{CFU} / \mathrm{g}$ of rice leaf SYX04 and SYX20 cells were detected immediately after inoculation (Fig. 1). After $24 \mathrm{~h}$, the abundance decreased to $1.3 \times 10^{7} \mathrm{CFU} / \mathrm{g}$ of leaf. After $72 \mathrm{~h}$, the cell counts in the leaves peaked at about $3 \times 10^{7} \mathrm{CFU} / \mathrm{g}$ of leaf. At 2 weeks, the bacterial counts had a small peak at about $6.6 \times 10^{6} \mathrm{CFU} / \mathrm{g}$ after which the cell counts decreased further. More than $5 \times 10^{6} \mathrm{CFU} / \mathrm{g}$ labeled strains were detected after 20 days in rice mature leaves and labeled strains could be also detected after 3 days in rice newly grown leaves. The colonization of B. subtilis SYX04 and SYX20 in rice plants suggests that the infection sites are probably occupied.

\section{Inhibition of conidial germination and appressorial formation of $M$. oryzae by $B$. subtilis}

The effects of $B$. subtilis against $M$. oryzae spore germination, germ tube elongation, and appressorial formation were assayed. Conidial germination and appressorial formation were significantly reduced by all four B. subtilis treatments compared to the control. Different treatments affected the germination and appressorial formation of M. oryzae in different ways (Table 1). The high percentage of inhibition of conidial germination shows that B. subtilis SYX04 and SYX20 can suppress development of M. oryzae.

Spore germination was found to be significantly inhibited by liquid culture of SYX04 and SYX20, and a similar trend was observed for germ tube length. Samples treated

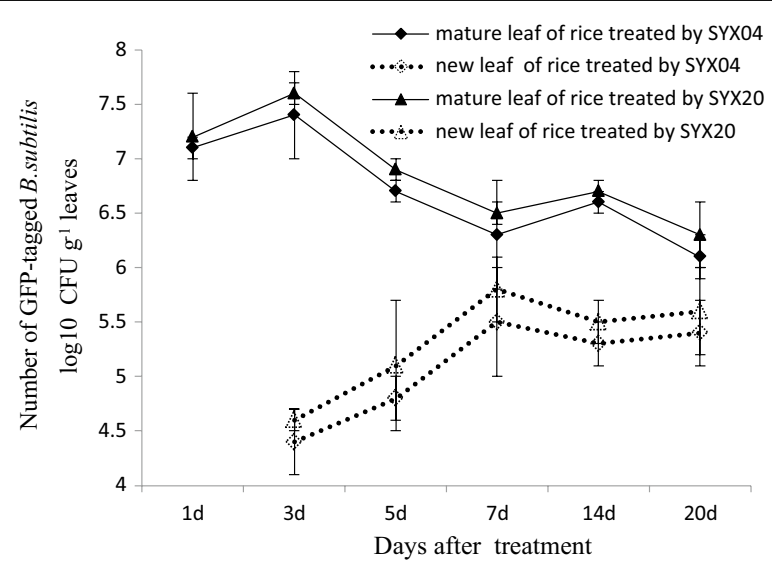

Fig. 1 Bacterial cell counts in the rice plants after inoculation with GFP-tagged B. subtilis SYX04 and SYX2O. On 1-2 days after inoculation, rice grew short new leaves and it was difficult to collect leaf samples. Starting from 3 days after inoculation, the colonization of new leaves was counted. The error bars indicate the SD of the mean calculated from three independent samples 
Table 1 Spore germination and germ tube length of $M$. oryzae P131 co-cultured with cells or sterile culture filtrate of Bacillus subtilis strains SYX04 and SYX20

\begin{tabular}{|c|c|c|c|c|c|c|}
\hline \multirow[t]{2}{*}{ Treatment } & \multicolumn{2}{|c|}{ Conidia germination } & \multicolumn{2}{|c|}{ Appressorial formation } & \multicolumn{2}{|l|}{ Germ tubes } \\
\hline & Number & Inhibition (\%) & Number & Inhibition (\%) & Length $(\mu \mathrm{m})$ & Inhibition (\%) \\
\hline SYX20 culture & $7 \pm 0.6 \mathrm{~d}$ & $93.3 \pm 0.6$ & $5 \pm 0.3 c$ & $93.8 \pm 0.8$ & $12.2 \pm 2.2 \mathrm{c}$ & $88.3 \pm 2.1$ \\
\hline SYX20 filtrate & $27 \pm 1.0 b$ & $72.7 \pm 1.0$ & $24 \pm 1.0 b$ & $72.1 \pm 0.3$ & $27.6 \pm 0.6 b$ & $73.5 \pm 0.6$ \\
\hline SYX04 culture & $9 \pm 1.2 \mathrm{~d}$ & $91.3 \pm 1.2$ & $6 \pm 1.7 c$ & $93.0 \pm 2.2$ & $4.3 \pm 0.5 d$ & $95.9 \pm 0.5$ \\
\hline SYX04 filtrate & $23 \pm 2.9 c$ & $76.8 \pm 3.5$ & $22 \pm 1.2 b$ & $73.3 \pm 1.4$ & $27.8 \pm 7.5 b$ & $73.3 \pm 7.6$ \\
\hline Control & $99 \pm 0.6 \mathrm{a}$ & - & $86 \pm 2.0 \mathrm{a}$ & - & $104.3 \pm 5.4 \mathrm{a}$ & - \\
\hline
\end{tabular}

SYX20 culture here refers to liquid culture of $B$. subtilis SYX20; SYX20 filtrate refers to culture filtrate of B. subtilis SYX20; SYX04 culture refers to liquid culture of B. subtilis SYX04; SYX04 filtrate refers to culture filtrate of B. subtilis SYX04; control refers to $M$. oryzae P131 alone. Data were first tested for normality and then analyzed using ANOVA. Significant differences between the mean values of each cohort were determined using LSD's test $(P=0.05)$ following one-way ANOVA. The data is computed at $P=0.05 \pm \mathrm{SD}$

with liquid culture of SYX20 showed a 93.30 and $93.8 \%$ inhibition of spore germination and appressorial formation, respectively. Spore germination and germ tube length were higher in response to culture filtrate containing SYX20, compared to the results for the SYX20 liquid culture. As SYX04 went from liquid culture to culture filtrate, length range of germ tube of M. oryzae P131 was from 4.3 to $27.8 \mu \mathrm{m}$. Liquid culture of SYX04 also inhibited conidial germination and appressorial formation.

The results show an abnormally thick and wide germ tube caused by B. subtilis SYX20. The defective germ tubes and abnormal appressoria were observed, probably due to abnormal conidia germination caused by B. subtilis SYX04. The inhibition of germination, reduction in the number of conidia with normal appressoria, and the formation of conidia with defective appressoria, can result in suppression of rice blast.

\section{Electron microscope analysis of $M$. oryzae P131}

The hyphae of $M$. oryzae P131 without antagonistic bacteria had a complete tubular shape and were morphologically normal observed by SEM (Fig. 2a). The hyphae treated with B. subtilis SYX04 culture, showed shrinkage, partial distortion, roughness, and wrinkling of the surface, indicating overall morphological abnormality (Fig. 2b). The hyphae treated with B. subtilis SYX20 culture displayed swelling and partial distortion (Fig. 2c). The hyphae tips treated with B. subtilis SYX04 and SYX20 also showed these
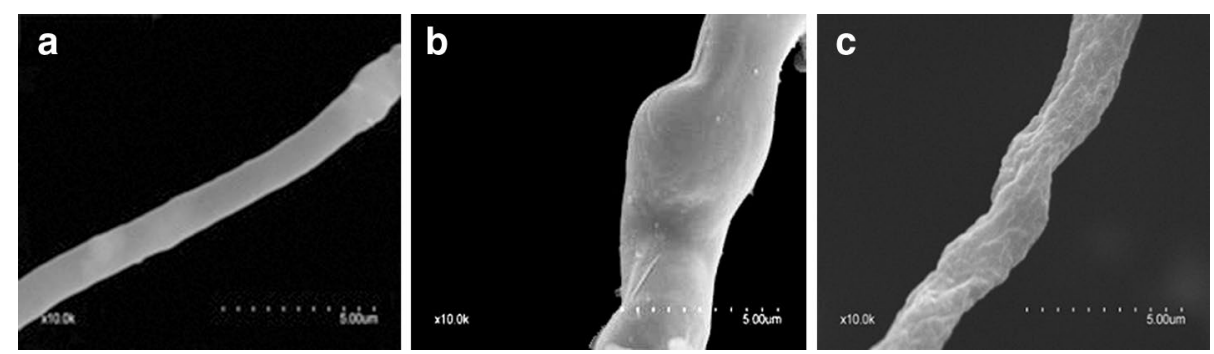

Fig. 2 Scanning electron micrographs of M. oryzae: Hyphae exposed to liquid culture of a water, $\mathbf{b} B$. subtilis SYX20, c B. subtilis SYX04. Scale bar $5 \mu \mathrm{m}$. Growth inhibition at the hyphal tips was observed in B. subtilistreated fungal cultures. Scale bar $10 \mu \mathrm{m}$. Arrows and arrowheads hyphae shrinkage and partial distortion, respectively 
morphological changes also. The hyphae tips of $M$. oryzae P131 without antagonistic bacteria were observed using SEM, which had a finely rounded terminus. After exposure to $B$. subtilis SYX04, the hyphae tips showed tapering and shrinkage, while the hyphae tips treated with B. subtilis SYX20 displayed tapering and partial inflation.

The conidia of $M$. oryzae P131 without antagonistic bacteria formed morphologically normal appressoria, as observed under SEM (Fig. 3a). After exposure to B. subtilis SYX04 and SYX20, the cell wall of conidia appeared to be degraded severely (Fig. 3b, c).

A more detailed analysis of the effect of B. subtilis SYX04 and SYX20 on fungal cells was performed using TEM (Fig. 4). The hyphae of M. oryzae P131 without antagonistic bacteria displayed typical eukaryotic cytoplasmic components enclosed by an electron-transparent cell wall (Fig. 4a-c), here indicated with boxes and arrows, observed under TEM. However, mycelia that had been treated with liquid culture of B. subtilis displayed ultrastructural abnormalities in the hyphal and conidial morphology structure. After exposure to liquid culture of B. subtilis SYX04, the cell walls of M. oryzae P131 hyphae appeared rough, and the cytoplasm separated from the cell wall (Fig. 4e), indicated with arrows. The cytoplasm of some conidia separated from cell wall of conidia (Fig. 4d), emphasized with boxes. When hyphae and conidia were exposed to liquid culture of B. subtilis SYX20, the cellular degradation was severe (Fig. 4f, g) with the presence of indiscernible organelles in the cytoplasm. The cell wall was severely degraded and cytoplasm had exfoliated from the cell wall, indicated with boxes. The co-culture time at $24 \mathrm{~h}$, observation made by TEM indicated that the cytoplasm in conidia had almost completely disappeared and the cell wall had become severely degraded. Such morphological changes were also evident in hyphae.

Overall, the cells of M. oryzae P131 treated with liquid culture of B. subtilis SYX04 and SYX20 exhibited abnormal morphology and cellular disorganization, suggesting that SYX04 and SYX20 degrade the cell wall, destroy the cell membrane, and damage cellular organelles.

\section{Induction of defense enzymes}

The activity of PO increased gradually, peaking at 2 days after inoculation (Fig. 5), showing about a two-fold increase in PO levels. PO levels were significantly different in leaves treated with the mixture compared with those treated with $M$. oryzae or B. subtilis alone. However, PPO activity was significantly higher in plants treated with B. subtilis

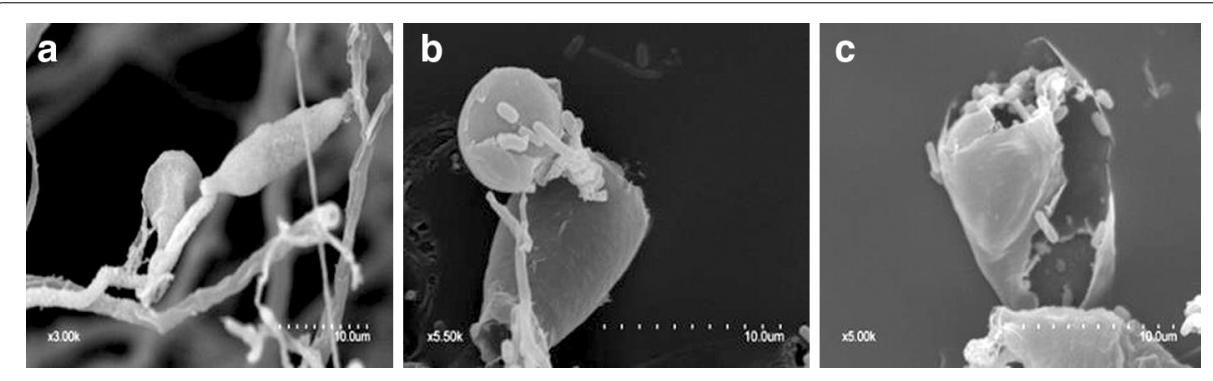

Fig. 3 M. oryzae conidia grown in the $\mathbf{a}$ absence of either agent or $\mathbf{b}$ presence of B. subtilis SYX20 and c B. subtilis SYXO4 at a concentration of $1 \times 10^{8} \mathrm{CFU} / \mathrm{g}$. Fungal and liquid culture of B. subtilis co-cultured at $12 \mathrm{~h}$ were examined using a S-3400N scanning electron microscope. Scale bar $10 \mu \mathrm{m}$ 
alone than in all other treatments after 2 days (Fig. 6). The activity on the second day increased three-fold and a gradual decrease was observed on the third day. The highest activity of plants treated with B. subtilis SYX04 was observed on the second day, and the PPO activity of plants treated with $M$. oryzae alone was lower than that of those treated with the mixture of $M$. oryzae and B. subtilis. The activity decreased on the second day of treatment. As shown in Fig. 7, the activities of superoxide dismutase (SOD) in the rice increased dramatically after treatment with liquid culture of B. subtilis SYX04 and SYX20 alone, but activity was highest on the first day. The SOD activity of plants treated with the mixture of M. oryzae and B. subtilis was higher than that of those treated with $M$. oryzae alone on the first day. PO, PPO and SOD associated with disease resistance characteristics were induced in the rice plants sprayed with B. subtilis SYX04 and SYX20.

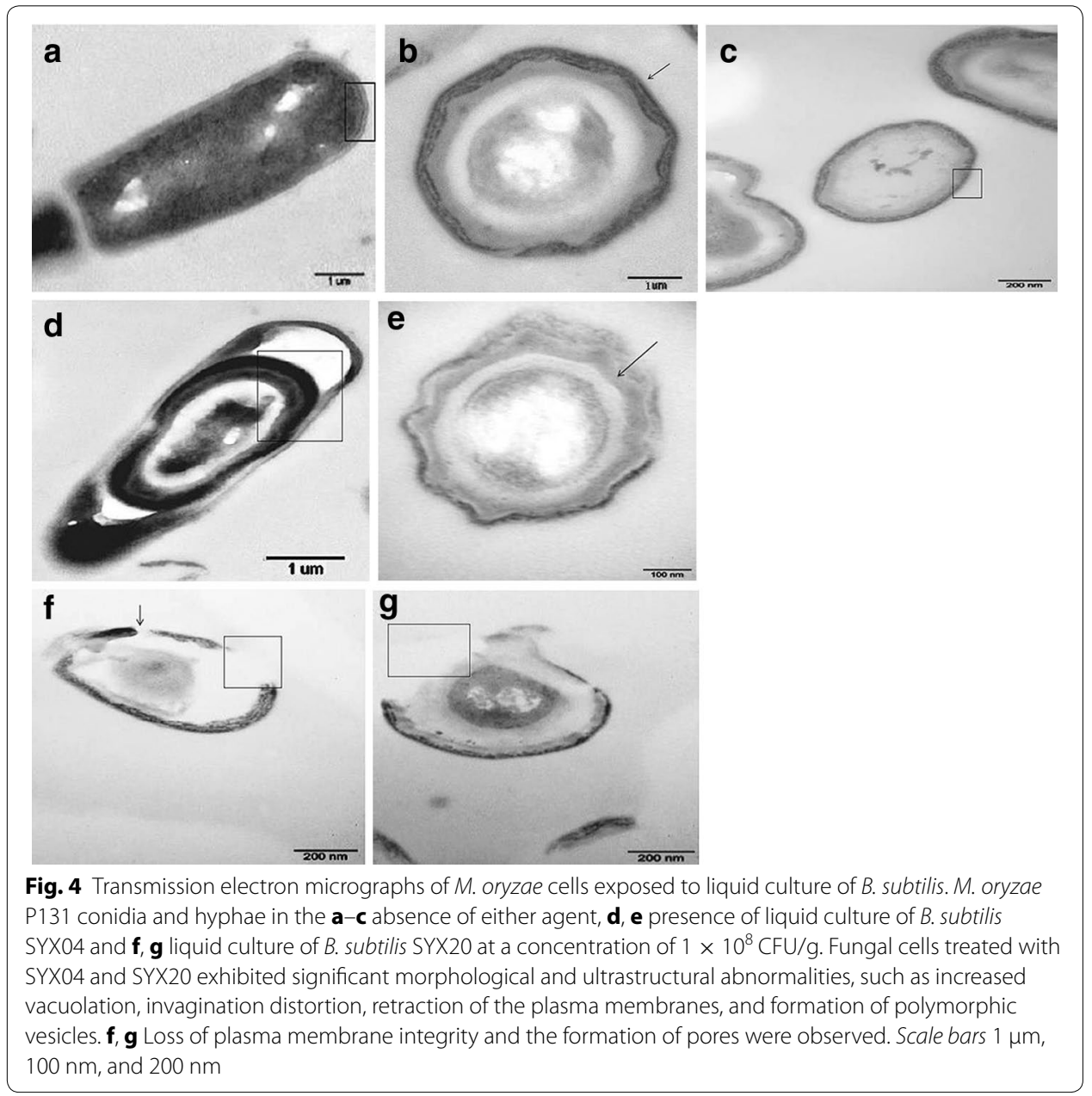




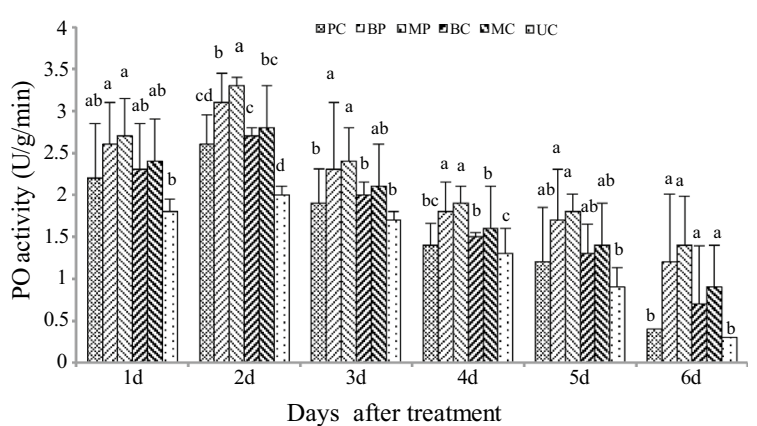

Fig. 5 Quantitative changes in plant defense enzymes (PO) in biocontrol of rice blast. Treated with a mixture of fermentation broth of SYXO4 and pathogen infection (BP); treated with a mixture of fermentation broth of SYX20 and pathogen infection (MP); treated with a fermentation broth control of SYX04 (BC); treated with a fermentation broth control of SYX2O (MC); treated with a pathogen control (PC); and untreated control (UC). Mean values are based on three replicates. Bars represent SD

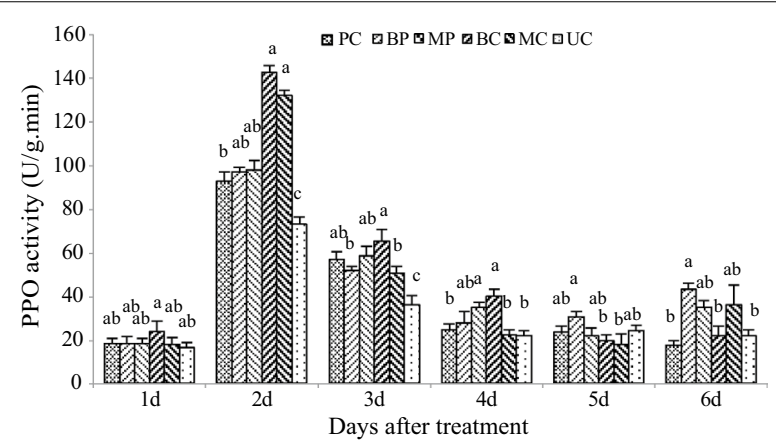

Fig. 6 Quantitative changes in plant defense enzymes (PPO) in biocontrol of rice blast. Treated with a mixture of fermentation broth of SYX04 and pathogen infection (BP); treated with a mixture of fermentation broth of SYX20 and pathogen infection (MP); treated with a fermentation broth control of SYX04 (BC); treated with a fermentation broth control of SYX2O (MC); treated with a pathogen control (PC); and untreated control (UC). Mean values are based on three replicates. Bars represent SE

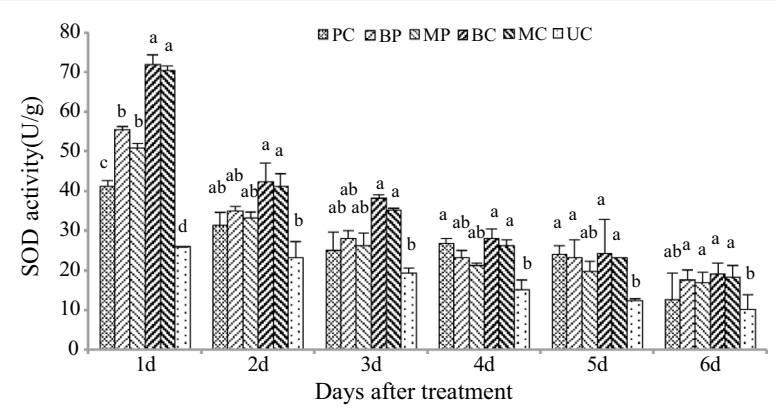

Fig. 7 Quantitative changes in plant defense enzymes (SOD) in biocontrol of rice blast. Treated with a mixture of fermentation broth of SYXO4 and pathogen infection (BP); treated with a mixture of fermentation broth of SYX20 and pathogen infection (MP); treated with a fermentation broth control of SYX04 (BC); treated with a fermentation broth control of SYX2O (MC); treated with a pathogen control (PC); and untreated control (UC). Mean values are based on three replicates. Bars represent SE 


\section{Discussion}

In this research, the interaction between B. subtilis and rice plants was studied for the purpose of assessing potential biocontrol mechanisms for rice blast. Many reports indicate that Bacillus strains are beneficial to stimulation of plant growth and disease resistance. Previously, B. subtilis strains were used as biological control agents, in which capacity they played an agriculturally important role in biocontrol of several plant pathogens, including M. oryzae (Zhang et al. 2014; Leelasuphakul et al. 2006). B. subtilis activity rely on special biological control mechanisms that Bacillus spp. can compete for colonization sites in plants, form biofilms, and enhance the provision of nutrients and phytohormones; improve interaction of pathogen and plant; and inhibit growth of the pathogen by antibiotics (Surfactin, Iturin and Fengycin), toxins, and biosurfactants; and a mechanism associated with bacteriolysis, involves production of extracellular cell wall degrading enzymes such as chitinase and $\beta$-1,3-glucanase (Chernin and Chet 2002; Li et al. 2014; Whipps 2001).

Better knowledge responsible for successful biological control on the basis of plantassociated antagonists including the complex regulation of disease suppression associated with bacteriolysis and inhibition of growth of the pathogen by antagonists; the dynamics and composition of plant-associated bacterial communities and colonization sites in plants (Normander and Prosser 2000). To investigate the distribution of GFPtagged B. subtilis SYX04 and SYX20 in rice plants further, the bacterial populations in the rice plant was monitored. It has been reported that labeled Bacillus NB12 could also be detected after 10 days on newly grown rice leaves that had been exposed to Rhizoctonia solani (Zhang et al. 2012). B. methylotrophicus BC79 could colonize rice leaves. Its population in the leaves $\left(1.65 \times 10^{8} \mathrm{CFU} / \mathrm{g}\right)$ was much larger than in the stems $\left(6.78 \times 10^{7} \mathrm{CFU} / \mathrm{g}\right)$ or the roots $\left(3.56 \times 10^{7} \mathrm{CFU} / \mathrm{g}\right)$ after 10 days of inoculation. The current results differed from those of previous studies of B. subtilis (Fig. 1). There is little information about colonization of $B$. subtilis in rice plant towards $M$. oryzae. Due to loss of the GFP-expressing plasmids, the GFP-expressing bacterial population was assayed in rice leaves only 20 days after inoculation. Further research should be performed to detect the bacterial populations of strains SYX04 and SYX20 in rice leaves after one or 2 months of inoculation. They should be labeled with double antibiotics or other markers.

Studies on the interactions between M. oryzae in rice and Bacillus sp., and the mechanisms of in vivo biological control are important to the adoption of adequate control measures for rice blast which are ecologically sustainable. Wang et al. (2012) described the molecular mechanisms involved in B. cereus-rice interactions. Xyloglucan endotransglycosylase may be involved in rice cell elongation processes due to up-regulation by treatment with Bacillus strains (Jan et al. 2004). The antagonist-pathogen interaction of B. subtilis KB-1122 and M. oryzae has been studied using comparative proteome analysis (Zhang et al. 2014). SEM results showed that citral inhibited hyphal growth of M. oryzae and reduced spore germination and germ tube length (Li et al. 2014). Taguchi et al. (2003), Jia et al. (2011), and Zhang et al. (2014) also found that hyphal morphology became irregular when the fungus was treated with specific biological control agents. Further research is needed to understand mechanisms of vital antibacterial substance produced by strains SYX04 and SYX20. 
TEM results showed that citral caused hyphal morphological and structural alterations (Li et al. 2014). Harish et al. (1998) reported that in vitro interaction of F. udum and B. subtilis strain AF 1 formed chlamydospore-like structures and increased vacuolation in the mycelium, when both cultures were simultaneously inoculated in PDB. These observations were consistent with reports showing the degradation of fungal cell walls treated with fermentation culture of B. subtilis NSRS89-24 (Leelasuphakul et al. 2006). The results showed that spore germination, germ tube length, and appressorium formation were significantly inhibited by liquid culture of SYX04 and SYX20 (Table 1) and a similar trend was observed for ultrastructural abnormalities in the hyphal and conidial morphology (Fig. 4). After exposure to B. subtilis SYX04 and SYX20, the hyphae displayed partial distortion, severely degraded cell walls and cytoplasm that had exfoliated from the cell wall (Figs. 2, 3). The results indicated that B. subtilis SYX04 and SYX20 may secrete molecules that mediate the interaction as early as $12 \mathrm{~h}$ after incubation. Further studies are necessary for identifying the elicitor molecules during the initial stages of the rice- $M$. oryzae interaction.

The defensive capacity was found to be enhanced when a plant was stimulated by biological control agents (van Loon et al. 1998). When rice seedlings were infected by pathogens, the increased activity of various defense-related enzymes and chemicals was found to enhance ISR (Chithrashree et al. 2011). The peroxidase activity in rice leaves infected by M. oryzae exhibited an increase (Wang et al. 1991; Sena et al. 2013). Peroxidase is related to diverse responses to plant stress. PO can reduce pathogen viability and spreading directly and indirectly because its enzymatic activity is relevant to the production and modulation of active oxygen species (Lamb and Dixon 1997). PPO can terminate oxidation of diseased plant tissue, and its enzymatic activity contributes to its role in disease resistance (Kosuge 1969). Guo and Li (2014) have researched Paenibacillus kribbensis PS04 for induction of plant resistance in the control of $R$. solani in rice. The application of a mixture of both B. subtilis and M. oryzae resulted in the induction of more PO activity against $M$. oryzae in rice plants than B. subtilis alone (Fig. 5). PPO and SOD activity in plants treated with $B$. subtilis alone were significantly higher than in all other treatments after inoculation (Figs. 6, 7). The results presented herein allow us to conclude that Bacillus sp. can induce plant defense mechanisms in rice, but the metabolic pathway that is activated need to be studied further.

\section{Conclusions}

Bacillus subtilis SYX04 and SYX20 were found to significantly inhibit rice pathogen M. oryzae P131, elicite plant defense reaction, and colonize in rice leave. Strains SYX04 and SYX20 significantly suppressed the mycelial growth, conidial germination, and germ tube formation, and appressorial formation of M. oryzae. GFP-labeled strains of B. subtilis colonized rice mature leaves, reaching populations of more than $5 \times 10^{6} \mathrm{CFU} / \mathrm{g}$ after 20 days, and labeled strains could be also detected after 3 days on newly grown leaves. After Bacillus spp. treatment, expression of defense-related peroxidases (PO, PPO and SOD) increased significantly, and these enzymes may participate in the defense mechanisms of plants. This is the first detailed report of the interaction between GFP-tagged B. subtilis and rice plant was performed towards controlling of rice blast. 


\section{Authors' contributions}

YS designed the study, performed the experiments, and drafted the manuscript. QW and YL supervised the work. All authors read and approved the final manuscript.

\section{Author details}

1 Department of Plant Pathology, China Agricultural University, 2 West Yuanmingyuan Rd., Haidian District, Beijing 100193, China. ${ }^{2}$ Key Laboratory of Plant Pathology, Ministry of Agriculture, China Agricultural University, Beijing 100193, China.

\section{Acknowledgements}

The authors wish to express their sincere thanks and appreciation to the College of Biological Sciences, China Agricultural University for help in using SEM and TEM. This work was supported by the Public Welfare Industry (Agriculture) Project of China (No. 200903057).

\section{Competing interests}

The authors declare that they have no competing interests.

Received: 4 January 2016 Accepted: 18 July 2016

Published online: 02 August 2016

\section{References}

Anand T, Chandrasekaran A, Kuttalam S, Senthilraja G, Samiyappan R (2010) Integrated control of fruit rot and powdery mildew of chilli using the biocontrol agent Pseudomonas fluorescens and a chemical fungicide. Biol Control 52:1-7

Chernin L, Chet I (2002) Microbial enzymes in the biocontrol of plant pathogens and pests. Enzymes in the environment: activity, ecology and applications. Marcel Dekker, Inc., New York, pp 171-226

Chithrashree Udayashankar AC, Nayaka SC, Reddy MS, Srinivas C (2011) Plant growth-promoting rhizobacteria mediate induced systemic resistance in rice against bacterial leaf blight caused by Xanthomonas oryzae pv. oryzae. Biol Control 59:114-122

Dagdas YF, Yoshino K, Dagdas G, Ryder LS, Bielska E, Steinberg G, Talbot NJ (2012) Septin-mediated plant cell Invasion by the rice blast fungus, Magnaporthe oryzae. Science 336:1590-1595

Dhindsa RS, Plumb-Dhindsa P, Thorpe TA (1981) Leaf senescence: correlated with increased level of membrane-permeability, lipid-peroxidation and decreased level of SOD and CAT. J Exp Bot 32:93-101

Dunn AK, Handelsman J (1999) A vector for promoter trapping in Bacillus cereus. Gene 226:297-305

FAO (2012) Economic growth is necessary but not sufficient to accelerate reduction of hunger and malnutrition. The State of Food Insecurity in the World. FAO, Rome

Grover M, Nain L, Singh SB, Saxena AK (2010) Molecular and biochemical approaches for characterization of antifungal trait of a potent biocontrol agent Bacillus subtilis RP24. Curr Microbiol 60:99-106

Guo T, Li MD (2014) Suppression of Rhizoctonia solani and induction of host plant resistance by Paenibacillus kribbensis PS04 towards controlling of rice sheath blight. Biocontrol Sci Technol 24:116-121

Hammerschimidt R, Nuckles E, Kuc J (1982) Association of enhanced peroxidase activity with induced systemic resistance of cucumber to Colletotrichum lagenarium. Physiol Plant Pathol 20:73-82

Harish S, Manjula K, Podile AR (1998) Fusarium udum is resistant to the mycolytic activity of a biocontrol strain of Bacillus subtilis AF 1. FEMS Microbiol Ecol 25:385-390

Hoitink HAJ, Boehm MJ (1999) Biocontrol within the context of soil microbial communities: a substrate-dependent phenomenon. Annu Rev Phytopathol 37:427-446

Jan A, Yang G, Nakamura H (2004) Characterization of a xyloglucan endotransglucosylase gene that is up-regulated by gibberellin in rice. Plant Physiol 136:3670-3681

Ji SH, Gururani MA, Chun SC (2014) Expression analysis of rice pathogenesis-related proteins involved in stress response and endophytic colonization properties of gfp-tagged Bacillus subtilis CB-R05. Appl Biochem Biotech 17:231-241

Jia SJ, Zeng DX, Wu XL, Tu G (2011) Inhibitory of an antifungal protein produced by Bacillus subtilis C-D6 against Magnaporthe oryzae. CN J Biol Control 27:362-367

Kobayashi N, Telebanco-Yanoria MJ, Tsunematsu H, Kato H, Imbe T, Fukuta Y (2007) Development of new sets of international standard differential varieties for blast resistance in rice (Oryza sativa L.). Jpn Agric Res Q 41:31-37

Kong XY, Han BQ, Li H, Liang Y, Shao K, Liu WS (2012) New biodegradable small-diameter artificial vascular prosthesis: a feasibility study. J Biomed Mater Res A 6:1494-1504

Kosuge T (1969) The role of phenolics in host response to infection. Annu Rev Phytopathol 7:195-222

Kumar KVK, Yellareddygari SK, Reddy MS, Kloepper JW, Lawrence KS, Miller ME, Sudini H, Reddy ECS, Zhou XG, Groth DE (2013) Ultrastructural studies on the interaction between Bacillus subtilis MBI 600 (Integral) and the rice sheath blight pathogen, Rhizoctonia solani. Afr J Microbiol Res 7(19):2078-2086

Lamb C, Dixon RA (1997) The oxidative burst in plant disease resistance. Annu Rev Plant Physiol Mol Biol 48:251-275

Leelasuphakul W, Sivanunsakul P, Phongpaichit S (2006) Purification, characterization and synergistic activity of beta-1, 3-glucanase and antibiotic extract from an antagonistic Bacillus subtilis NSRS 89-24 against rice blast and sheath blight. Enzyme Microb Technol 38:990-997

Li L, Steffens JC (2002) Overexpression of polyphenol oxidase in transgenic tomato plants results in enhanced bacterial disease resistance. Planta 215:239-247

Li L, Yang C, Liu ZD, Li FD, Yu ZN (2000) Screening of acrystalliferous mutants from Bacillus thuringiensis and their transformation properties. Acta Microbiol Sin 40:85-90

Li RY, Wu XM, Yin XH, Liang JN, Li M (2014) The natural product citral can cause significant damage to the hyphal cell walls of Magnaporthe grisea. Molecules 19:10279-10290 
Liu XM, Zhao HX, Chen SF (2006) Colonization of maize and rice plants by strain Bacillus megaterium C4. Curr Microbiol 52:186-190

Mariné MCH (1992) A simple way to encapsulate small samples for processing for TEM. J Microsc 168:203-206

Muthayya S, Sugimoto JD, Montgomery S, Maberly GF (2014) An overview of global rice production, supply, trade, and consumption. Ann NY Acad Sci 1324:7-14

Normander B, Prosser J (2000) Bacterial origin and community composition in the barley phytosphere as a function of habitat and presowing conditions. Appl Environ Microb 66:4372-4377

Sena APA, Chaibub AA, Cortes MVCB, Silva GB, Silva-Lobo VL, Prabhu AS, Filippi MCC, Araujo LG (2013) Increased enzymatic activity in rice leaf blast suppression by crude extract of Epicoccum sp. Trop Plant Pathol 38:387-397

Sha YX, Li Y, Wang Q (2014) The potential biocontrol agent against Magnaporthe oryzae isolated from Southwest Territories of China. In: Abstracts of the 5th Asian conference on plant pathology, Thai Phyopathological Society, Chiang Mai, 3-6 November 2014

Shan HY, Zhao MM, Chen DX, Cheng JL, Li J, Feng ZZ, Ma ZY, An DR (2013) Biocontrol of rice blast by the phenaminomethylacetic acid producer of Bacillus methylotrophicus strain BC79. Crop Prot 44:29-37

Skamnioti P, Gurr SJ (2009) Against the grain: safeguarding rice from rice blast disease. Trends Biotechnol 27:141-150

Strunnikova OK, Vishnevskaya NA, Ruchiy AS, Shakhnazarova VY, Vorobyov NI, Chebotar VK (2015) The influence of soils with different textures on development, colonization capacity and interactions between Fusarium culmorum and Pseudomonas fluorescens in soil and on barley roots. Plant Soil 389(1-2):131-144

Taguchi Y, Hyakumachi M, Horinouchi H, Kawane F (2003) Biological control of rice blast disease by Bacillus subtilis IK-1080. Jpn J Phytopathol 69:85-93

Tian T, Qi XC, Wang Q, Mei RH (2004) Colonization study of GFP-tagged Bacillus strains on wheat surface. Acta Phytopathol Sin 34:346-351

van Loon LC, Bakker PAHM, Pieterse CMJ (1998) Systemic resistance induced by rhizosphere bacteria. Annu Rev Phytopathol 36:453-483

Wang SY, Jiao HJ, Faust M (1991) Changes in the activities of catalase, peroxidase, and polyphenol oxidase in apple buds during bud break induced by thidiazuron. J Plant Growth Regul 10:33-39

Wang W, Chen LN, Wu H, Zang H, Gao S, Yang Y, Xie S, Gao X (2012) Comparative proteomic analysis of rice seedlings in response to inoculation with Bacillus cereus. Lett Appl Microbiol 56:208-215

Whipps JM (2001) Microbial interactions and biocontrol in the rhizosphere. J Exp Bot 52:487-511

Yamaguchi I (2004) Overview on the chemical control of rice blast disease. In: Kawasaki S (ed) Rice blast: interaction with rice and control. 3rd international rice blast conference, Tsukuba, Japan, 2002

Yan QH, Zhou JX, Li HZ, Zhi QQ, Zhou XP, He ZM (2015) Coexistence of and interaction relationships between an aflatoxin-producing fungus and a bacterium. Fungal Biol 119(7):605-614

Zarandi ME, Bonjar GHS, Dehkaei FP, Moosavi SAA, Farokhi PR, Aghighi S (2009) Biological control of rice blast (Magnaporthe oryzae) by use of Streptomyces sindeneusis isolate 263 in greenhouse. Am J Appl Sci 6:194-199

Zhang DT, Peng ZK, Cao QQ, Yang M, Zheng L, Zhou EX (2012) Colonization of three antagonistic strains on rice plant and their biocontrol effects on rice sheath blight. J Northwest A\&F Univ 40:97-102

Zhang YL, Li S, Jiang DH, Kong LC, Zhang PH, Xu JD (2013) Antifungal activities of metabolites produced by a termiteassociated Streptomyces canus BYB02. J Agri Food Chem 61:1521-1524

Zhang CX, Zhang XX, Shen SH (2014) Proteome analysis for antifungal effects of Bacillus subtilis KB-1122 on Magnaporthe grisea P131. World J Microb Biot 30:1763-1774

\section{Submit your manuscript to a SpringerOpen ${ }^{\circ}$ journal and benefit from:}

- Convenient online submission

- Rigorous peer review

Immediate publication on acceptance

- Open access: articles freely available online

- High visibility within the field

- Retaining the copyright to your article

Submit your next manuscript at $>$ springeropen.com 